\title{
AS COMPETÊNCIAS CONTEMPORÂNEAS DO SECRETÁRIO EXECUTIVO E A RELAÇÃO COM AS COMPETÊNCIAS DO MIDDLE MANAGER
}

\author{
THE CONTEMPORARY EXECUTIVE SECRETARY'S
} AND THEIR RELATIONSHIP TO THOSE OF THE MIDDLE MANAGER

\author{
Katia Denise Moreira \\ Doutoranda em Administração pela Universidade Federal de Santa Catarina (UFSC). \\ Secretária Executiva do Gabinete da Reitoria UFSC. \\ E-mail: katiadenise@yahoo.com.br (Brasil)
}

\section{Luci Mari Aparecida Rodrigues}

Mestranda em Administração pela Universidade Federal de Santa Catarina (UFSC).

Secretária Executiva da UFSC.

E-mail: lurodrigues85@gmail.com (Brasil)

\section{Juliana Cidrack Freire do Vale}

Mestre em Administração e Controladoria pela Universidade Federal do Ceará (UFC).

Secretária Executiva da Universidade Federal de Santa Catarina - UFSC.

E-mail: julianacidrack@gmail.com (Brasil)

\section{Marize Helena da Rosa}

Mestranda em Administração pela Universidade Estadual do Centro-Oeste (UNICENTRO).

Secretária Executiva da Universidade Federal da Fronteira Sul (UFFS).

E- mail: marize00@ gmail.com (Brasil) 


\title{
AS COMPETÊNCIAS CONTEMPORÂNEAS DO SECRETÁRIO EXECUTIVO E A RELAÇÃO COM AS COMPETÊNCIAS DO MIDDLE MANAGER
}

\section{RESUMO}

À medida que se considera o profissional do Secretariado Executivo como atuante junto às posições de liderança, pressupõe-se que haja correlação entre as competências desse profissional e aquelas do middle manager. Realizou-se, então, esta pesquisa de abordagem qualitativa e descritiva, na qual se procurou analisar a possível natureza de tal correlação. Trata-se de uma pesquisa bibliográfica, baseada em livros, artigos, leis e outros documentos que tratam do assunto. Após se elencar as competências e funções de ambos os profissionais, os dados levantados foram categorizados e analisados a partir da tipologia da gerência intermediária elaborada por Floyd e Wooldridge (1992), com o auxílio da técnica de Análise de Conteúdo. Como resultado, confirmou-se, em âmbito teórico, uma forte correlação entre as funções e competências daqueles profissionais.

Palavras-chave: competências; secretário executivo; middle manager.

\section{THE CONTEMPORARY EXECUTIVE SECRETARY'S AND THEIR RELATIONSHIP TO THOSE OF THE MIDDLE MANAGER}

\begin{abstract}
As Executive Secretariat professionals are considered to work along with leadership positions, these professionals' and those middle managers' skills are supposed to be correlated. Therefore, this qualitative and descriptive research was conducted with the purpose of analyzing the possible nature of such correlation. This is a bibliographic research, based on books, articles, law articles, and other documents on the subject. After listing both professionals's skills and roles, the surveyed data were characterized and analyzed from the typology of middle management, elaborated by Floyd \& Wooldridge (1992), with the assistance of the Content Analysis technique. As a result, a strong correlation between the roles and the sets of skills of these professionals was confirmed, on a theoretical basis.
\end{abstract}

Keywords: skills; executive secretary; middle manager. 


\section{Introdução}

Ao longo da história do secretariado observa-se que o profissional sempre realizou atividades importantes, tanto no que diz respeito às tarefas de rotina quanto naquelas administrativas, em setores públicos e privados. O avanço da automação nos escritórios proporcionou uma redução em demandas repetitivas e extenuantes, o que permitiu aos trabalhadores secretariais desenvolverem novas habilidades e assumirem atribuições mais integradas ao funcionamento dos escritórios (U. S. Department of Labor, 1985; Garfield, 1986).

Portela e Schumacher (2009) dissertam sobre o aprimoramento das funções do profissional de secretariado e afirmam que este possui visão ampla de gestão e assume um caráter inovador, proativo e empreendedor, cuja atuação se caracteriza por ele ser um agente de conexão entre clientes internos e externos, gerenciador de informações, administrador de procedimentos de trabalho e preparador e organizador de processos institucionais.

A partir de tais considerações, este estudo enfatiza a posição do profissional de Secretariado Executivo frente a cargos de liderança em nível tático nas organizações públicas e privadas. Isso porque, entende-se que as competências desse profissional o tornam apto para auxiliar na concretização de ações relativas às estratégias advindas da alta administração, para a qual também presta assessoria.

Ressalta-se que o recorte teórico foi definido com base no contexto brasileiro de atuação desse profissional, no sentido não de descaracterizar a profissão, mas sim de demonstrar, por meio de uma correlação analítica e reflexiva acerca dos estudos do campo da gestão, que o secretário executivo possui competências que o tornariam apto para atuar no gerenciamento intermediário em uma organização.

Nonaka (1988) menciona que o middle manager, gerente de nível médio ocupante de uma posição-chave na organização, é dotado de capacidades para combinar estratégias em nível micro e macro, cujo propósito é eliminar ruídos e flutuações no ambiente das organizações e, ainda, atuar, como um agente do processo de autorrenovação e mudança institucional. Assim, com base na premissa de que pode existir correlação entre o que profissional de Secretariado Executivo é e faz contemporaneamente e a atuação do middle manager, questiona-se: quais são as possíveis relações entre as competências do profissional de Secretariado Executivo e as do middle manager?

A fim de responder tal questionamento, este trabalho tem por objetivo analisar as possíveis relações entre as competências do profissional de Secretariado Executivo e aquelas do middle 
manager. Para tanto, como forma de alcançar o pressuposto, foram delineados os seguintes objetivos específicos: a) descrever as competências do profissional de Secretariado Executivo; b) caracterizar o middle manager e identificar suas competências c) correlacionar as competências entre profissionais de Secretariado Executivo e do middle manager.

O estudo se justifica pela importância da difusão de novas pesquisas na área secretarial. Além disso, emerge a necessidade de reflexão acerca das correlações possíveis entre as competências do secretário executivo e outras competências exigidas para a gestão organizacional diante de sua atuação como assessor e mediador.

Essa dimensão tem fundamento, ainda, na análise do contexto das instituições, tanto públicas como privadas, pois, à medida que atravessam um processo adaptação contínuo às demandas de seus ambientes de atuação, essas organizações têm buscado cada vez mais, profissionais capazes de atuar na gestão em nível tático, para que ocorra a implantação bemsucedida da estratégia organizacional.

\section{Fundamentação Teórica}

Nesta seção apresenta-se o arcabouço teórico que embasou este estudo e o alcance de seu objetivo. Assim, o tema competências é o elemento central, complementado pelas competências específicas do profissional de Secretariado Executivo e do middle manager.

\section{Breves Considerações sobre Competências}

No contexto organizacional, o tema competência tem sido trabalhado dentro de várias perspectivas de entendimento e aplicação. Dessa forma, seus significados e interpretações são diversos, dada a existência de um conjunto de fatores que abrangem o movimento das competências. Tal afirmativa é discutida por autores como: Burgoyne (1993), Carvalho (1998) e Paiva, Ésther e Pires (2006).

A partir da década de 1970, iniciam-se os registros mais significativos sobre tal temática, com os estudos de McClelland (1973), nos quais se procurou diferenciar competências de temas como aptidões, conhecimentos e habilidades. Dessa maneira, a competência assume uma característica mais subjacente, que permite ao indivíduo ter um desempenho diferenciado frente a uma tarefa ou situação. 
Outras discussões acerca do termo competência foram realizadas nos Estados Unidos (Escola Anglo-saxônica), que estruturaram a primeira definição do conceito, cuja perspectiva foi pensar as competências como um conjunto de conhecimentos, habilidades e atitudes, ou seja, o input para um desempenho superior (Parry, 1996 como citado em Filenga, Moura, \& Rama, 2010).

Já o debate suscitado pela Escola Francesa (Europeia) acerca do tema procurava ir além do conceito de qualificação; o entendimento era de que a concepção de competência deveria ser trazida na perspectiva de output (Fleury \& Fleury, 2004). Isto é, inferir nos resultados da organização, porque o fato de a pessoa deter um conjunto de conhecimentos, habilidades e atitudes, estes não garantiriam o benefício organizacional direto; daí a necessidade da entrega (Dutra, 2009). Desse modo, o conceito de competência é ampliado para contemplar, também, os resultados, a produção e a entrega para fins de agregação de valor à organização.

Verifica-se na literatura sobre competências duas instâncias de compreensão: no nível das pessoas (competências individuais) e no nível das organizações (competências organizacionais). O conceito de competência individual é a dimensão mais conhecida e difundida (Filenga, Moura \& Rama, 2010), cuja construção é mais antiga e heterogênea (Ruas, 2005), enquanto a noção de competência organizacional ganhou maior atenção após a publicação do artigo "The Core Competence of the Corporation", por Prahalad e Hamel (1990), que propõe o conceito de competências essenciais.

Diante do exposto, constata-se a existência de uma transição que perpassa as noções de competências em uma linha evolutiva conceitual, que vai do mecânico para o orgânico ou da concepção taylorista para a economia do saber (Bündchen, Rosseto \& Silva, 2011), sobre a qual é significativo salientar a importância das competências individuais, ou seja, aquelas que se desenvolvem no nível do indivíduo e, foi essa a primeira elaboração sobre o ponto de vista teórico do conceito de competências, com o artigo de McClelland (1973), o qual recebeu inúmeras outras contribuições, dentre as quais se destacam as de Zarifian (1994) e Le Boterf (1994).

Por outro lado, quando se pondera sobre o modelo estratégico de gestão de competências, existe a necessidade do alinhamento das competências individuais às organizacionais, para que se torne efetiva a agregação de valor econômico às instituições e de valor social ao indivíduo (Pereira \& Silva, 2011). A partir disso, os autores consideram que houve a exigência de uma nova concepção de profissionais capazes de lidar com as incertezas presentes nas organizações, o que direciona o enfoque para as competências gerenciais como alternativa promissora às constantes transições presentes nesse contexto. 
Para Resende (2000), as competências gerenciais são consideradas uma das principais tipologias de competência profissional, visto que proporcionam o apoio necessário a todas as áreas organizacionais e segundo o autor, podem ser definidas como: “[...] capacitações mais específicas da competência de gestão, compreendendo habilidades pessoais e conhecimentos de técnicas de administração ou gerenciamento, de aplicação em situações de direção, coordenação ou supervisão" (Resende, 2000, p. 60).

A gestão baseada nas competências surge, portanto, como alternativa para solução de problemas gerenciais, especialmente a partir da necessidade de alinhar pessoas e estratégias para ocupação de um posicionamento competitivo sustentável por parte das empresas, particularmente, no que concerne à articulação entre objetivos e entrega de resultados, circunstância que a leva ocupar um espaço cada vez mais significativo nos campos gerencial e científico (Weymer \& Silva, 2009).

Boyatzis (1982) recuperou diversos estudos sobre competências dos gerentes e identificou um conjunto de características e traços que, segundo ele, proporcionam um desempenho superior. Desse modo, a competência estava ligada ao paradigma taylorista-fordista e era uma forma mais moderna de trabalhar a qualificação dos funcionários, com o objetivo de obter desempenhos superiores. Definia-se um estoque de conhecimentos, habilidades e atitudes (CHA) que permitiam ao indivíduo, em seu cargo ou função, alcançar resultados diferenciados.

A Figura 1 ilustra o conceito de competência.

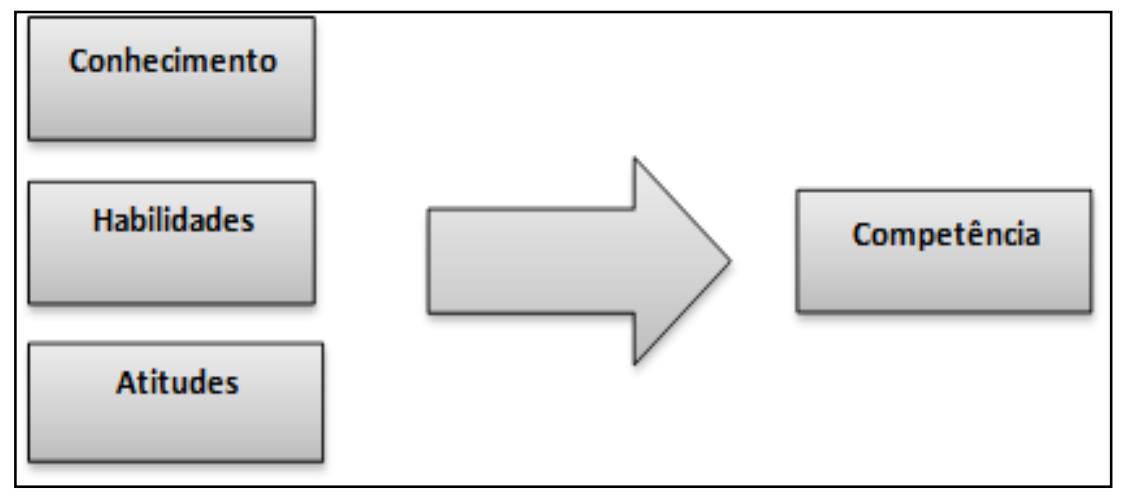

Figura1. Dimensões da Competência

Fonte: Elaborado pelas autoras com base em Magalhães, Wanderley e Rocha (1997).

A partir do apresentado, observa-se que as três dimensões: conhecimento, habilidades e atitudes, estão interligadas e significam, em outras palavras, ter o conhecimento para fazer algo, saber fazer e a ação de fazê-lo (Rabaglio, 2001), a Figura 2 demonstra o discutido. 


\begin{tabular}{|c|c|c|}
\hline \multicolumn{2}{|c|}{ Dimensões da Competência } \\
\hline C= Conhecimentos & H = Habilidades & A = Atitude \\
\hline $\begin{array}{c}\text { Escolaridade, conhecimentos } \\
\text { técnicos, cursos gerais e e } \\
\text { especializações. }\end{array}$ & saber. & $\begin{array}{l}\text { Aplicação dos conhecimentos } \\
\text { e prática do habilidades adquiridas e/ou a serem } \\
\text { adquiridas. }\end{array}$ \\
\hline SABER & SABER FAZER & QUERER FAZER \\
\hline
\end{tabular}

Figura 2. Dimensões da Competência

Fonte: Elaborado pelas autoras com base em Rabaglio (2001).

Segundo o exposto, constata-se que competência é o elemento fundamental para o profissional atualizado. Uma carreira linear não se ajusta mais aos padrões contemporâneos do mercado de trabalho e, segundo esse pressuposto, o secretário executivo precisaria desenvolver competências que o tornassem um profissional polivalente, fato esse que lhe permitiria atuar nas organizações desde o nível operacional até o tático, conforme o disposto neste estudo.

\section{Competências no Contexto do Secretário Executivo}

Os desafios do mercado de trabalho favorecem o aumento da demanda por profissionais “competentes", ou seja, aqueles que apresentam determinadas competências de acordo com a área de atuação e se mostram atentos às demandas organizacionais. Taylor (1970) já abordava as necessidades das empresas contarem com "homens eficientes" nos processos de trabalho. Nesse sentido, e, a partir dos princípios de seleção e treinamento do trabalhador, as organizações buscavam aperfeiçoar as habilidades específicas de seus funcionários, necessárias para o exercício de sua função. Tal ação, ou seja, a de identificar quais são as competências de um profissional, possibilita diagnosticar se ele está qualificado a desempenhar determinado papel organizacional.

A esse panorama se agregam as competências relacionadas ao profissional de Secretariado Executivo, com ênfase para aquelas que surgem como uma resposta diferenciada de capacitação; quesito que envolve reflexões importantes sobre o papel das pessoas no âmbito organizacional, o significado do trabalho e a educação profissional continuada.

Nesse contexto, destaca-se a mudança significativa que ocorreu em um período de sete anos nas atribuições do secretário executivo, como se pode observar na legislação da profissão. No Art. $3^{\circ}$ da lei n. 6. 556, de 5 de setembro de 1978, as atribuições do secretário: "a) executar tarefas relativas à anotação e redação, inclusive em idiomas estrangeiros; b) datilografar e organizar documentos; c) outros serviços de escritório, tais como: recepção, registro de compromisso e 
informações, principalmente junto a cargos diretivos da organização" Lei n. 6.556 (1978).

No art. $4^{\circ}$ da lei n. 7.377 , de 30 de setembro de 1985, as atribuições do secretário são:

I. planejamento, organização e direção de serviços de secretaria; II. assistência e assessoramento direto a executivos; III. coleta de informações para a consecução de objetivos e metas de empresas; IV. redação de textos profissionais especializados, inclusive em idioma estrangeiro; V. interpretação e sintetização de textos e documentos; VI. taquigrafia de ditados, discursos, conferências, palestras de explanações, inclusive em idioma estrangeiro; VII. versão e tradução em idioma estrangeiro, para atender às necessidades de comunicação da empresa; VIII. registro e distribuição de expedientes e outras tarefas correlatas; IX. orientação da avaliação e seleção da correspondência para fins de encaminhamento à chefia; conhecimentos protocolares (Lei n. 7.377, 1985).

Verifica-se, principalmente nos incisos I, II, III e VIII, a descrição dessa mudança de atribuições, quando se incorpora ao trabalho do profissional de secretariado autonomia decisória e atuação em vários níveis, o que vai ao encontro do que as organizações anseiam.

No Código Brasileiro de Ocupações do Ministério do Trabalho e Emprego, sob o código 2523, estão, também, inseridas competências para secretários executivos e bilíngues, relacionadas à postura profissional, à adaptabilidade às mudanças organizacionais, à empatia, ao autocontrole, ao dinamismo, à ética, à iniciativa, à liderança, à busca constante de conhecimentos, à boa comunicação, tanto na língua portuguesa, quanto em idiomas estrangeiros, dentre outras (Ministério do Trabalho e Emprego, 2002).

Outro documento que contempla as competências para o profissional em estudo são as Diretrizes Curriculares Nacionais para o Secretariado Executivo (Resolução da Câmara de Educação Superior n. 3, 2005), que no parágrafo único do artigo terceiro dispõe:

O bacharel em secretariado executivo deve apresentar sólida formação geral e humanística, com capacidade de análise, interpretação e articulação de conceitos e realidades inerentes à administração pública e privada, ser apto para o domínio em outros ramos do saber, desenvolvendo postura reflexiva e crítica que fomente a capacidade de gerir e administrar processos e pessoas, com observância dos níveis graduais de tomada de decisão, bem como capaz para atuar nos níveis de comportamento micro-organizacional, meso-organizacional e macro-organizacional (Resolução da Câmara de Educação Superior n. 3, 2005).

Embasados nas legislações apresentadas, vários autores apresentam e discutem as atribuições e competências do secretário, entre eles, Cordeiro (2009), que sintetizou o perfil atual deste profissional, em termos de aspectos comportamentais e competências, conforme segue:

Planejamento, organização e direção de serviços de secretaria; assistência e assessoramento direto a executivos; coleta de informações para a consecução de objetivos e metas de empresas; redação de textos profissionais especializados, inclusive em idioma estrangeiro; Interpretação e sintetização de textos e documentos; versão e tradução em idioma estrangeiro para atender as necessidades de comunicação da empresa; registro e distribuição de expedientes e outras tarefas correlatas; orientação da 
avaliação e seleção da correspondência para fins de encaminhamento à chefia; conhecimentos protocolares, organização de eventos; idiomas, técnicas secretariais, informática, arquivo; negociação, competência administrativa; motivação; capacidade de assumir serviços de apoio como PABX e recepção; comunicação; habilidade em áreas diversificadas como administração, economia, contabilidade, finanças, marketing, matemática financeira, legislação, recursos humanos, domínio da língua portuguesa; domínio de habilidades de escritório; planejamento, organização, liderança e controle de viagens, eventos, reuniões, agenda e arquivos; empreendedorismo, domínio de tecnologias; trabalho com a parte burocrática e de métodos; programação de soluções (Cordeiro, 2009, p. 34).

Diante do exposto nas diretrizes curriculares, nas leis, no Código Brasileiro de Ocupações do Ministério do Trabalho e Emprego e nas abordagens de autores que discutiram o tema anteriormente, destacam-se algumas das principais competências do secretário executivo para atuação nas organizações, conforme disposto na Figura 3:

\begin{tabular}{|c|c|}
\hline \multicolumn{2}{|c|}{ Competências contemporâneas dos profissionais de Secretariado Executivo } \\
\hline Aspectos relativos à técnica para o trabalho & Aspectos relativos à conduta profissional \\
\hline $\begin{array}{l}\text { Pensamento estratégico; organização; planejamento; } \\
\text { assistência e assessoramento; empreendedorismo; coleta de } \\
\text { informações; inovar e elaborar objetivos na organização; } \\
\text { administração do tempo; cooperativismo; gerenciamento de } \\
\text { informações; conhecimentos protocolares, organização de } \\
\text { eventos; idiomas; técnicas secretariais; registro e distribuição } \\
\text { de expedientes; domínio de habilidades de escritório e } \\
\text { tecnologias; programador de soluções; orientação da } \\
\text { avaliação e seleção da correspondência; conhecimento de } \\
\text { trâmites, normas e resoluções; mediação de conflitos; redação } \\
\text { de textos profissionais especializados; utilização de recursos e } \\
\text { softwares de comunicação e informação disponíveis; } \\
\text { raciocínio lógico; gestão de arquivos e processos; habilidade } \\
\text { em áreas diversificadas como administração, economia, } \\
\text { contabilidade, finanças, marketing, matemática financeira, } \\
\text { legislação, recursos humanos, domínio da língua portuguesa e } \\
\text { capacidade de identificar oportunidade de crescimento. }\end{array}$ & $\begin{array}{l}\text { Liderança, iniciativa; motivação; capacidade } \\
\text { de comunicação; capacidade de adaptação a } \\
\text { mudanças; ética profissional; responsabilidade; } \\
\text { dinamismo; autocontrole; flexibilidade; criatividade; } \\
\text { discrição; capacidade de } \\
\text { comprometimento; empatia; bom relacionamento } \\
\text { interpessoal; equilíbrio emocional; proatividade; bom } \\
\text { senso; profissionalismo; trabalho em equipe; } \\
\text { administração de conflitos; polivalência, } \\
\text { perceptividade; eficiência e eficácia; conhecimento da } \\
\text { empresa e visão da totalidade da empresa; dedicação; } \\
\text { pontualidade; assiduidade; sensibilidade; tomada de } \\
\text { decisões; delegação e atuação como agente facilitador. }\end{array}$ \\
\hline
\end{tabular}

\section{Figura 3. Competências contemporâneas dos Profissionais de Secretariado Executivo.}

Fonte: Elaborado pelas autoras, com base em Ministério do Trabalho e Emprego (2002); Resolução da Câmara de Educação Superior n. 3 (2005); Lei n. 6.556 (1978); Lei n. 7.377 (1985); Cordeiro (2009); Lima e Cantarotti (2010); Leal e Dalmau (2014). 
As competências ilustradas na Figura 3 ratificam o dito por Azevedo e Costa (2002), ou seja, que o mercado de trabalho busca profissionais preparados, que possam assessorar e tomar decisões; que atuam na gestão e que buscam constantemente aprendizagem de técnicas gerenciais, bem como tenham competência empreendedora. Corroboram com o exposto, Leal e Fiates (2013, p. 39) quando mencionam que:

A incorporação dessas novas competências permitiu que esses profissionais ocupassem um espaço significativo junto aos gestores, ao mesmo tempo em que viabilizou o desenvolvimento de um maior nível de autonomia. Tornaram-se, assim, capazes de intervir nos processos decisórios, identificar dificuldades e solucioná-las, analisar e interpretar informações, trabalhar em equipe e atuar como agentes de mudanças.

Nessa perspectiva, Natalense (1995) aponta que o secretário tem como funções o planejamento, a organização e o controle de seus trabalhos rotineiros, como reuniões, preparação de viagens, entre outras atividades de sua competência. Estas, alinhadas a atributos que englobam flexibilidade, criatividade, liderança, dinamismo, iniciativa, eficiência, discrição, cooperativismo, ética, comprometimento, tomada de decisão e paciência (Bortolotto \& Willers, 2005), possibilitam ao secretário executivo desenvolver competências para atuar em funções operacionais, como o controle de trabalhos rotineiros, e nas gerenciais, como distribuição de responsabilidades.

Natalense (1995) ressalta, ainda, que o secretário faz uso das habilidades como motivação, liderança e comunicação, além de "ter um total controle sobre suas emoções, suas atividades e a de seus subordinados" (Seiblitz, 1999, p. 32). Nesse sentido, o processo comunicativo verbal eficiente é uma preocupação primordial. Assim sendo, é essencial ao profissional de Secretariado ter entre suas principais competências a capacidade de se comunicar, na forma verbal e escrita, de maneira efetiva, tendo como finalidade a busca por resultados em prol da organização na qual atua (Mattos, 2000).

O profissional de Secretariado Executivo “Ainda é um negociador, programador de soluções, empreendedor, mostrando iniciativa, proatividade, comprometimento e participando em inúmeras atividades no ambiente de trabalho" (Lasta \& Durante, 2008, p. 54). Nessa perspectiva, o secretário:

[...] segue os princípios da administração empresarial: tomar decisões, solucionar conflitos e trabalhar em equipe. Separar fatos de opiniões, pensamentos de sentimentos e aplicá-los, levando em conta as consequências das ações escolhidas. Desenvolver habilidades de comunicação, como saber ouvir e perguntar, expressar-se de forma oral e escrita corretamente (Garcia, 1999, p.43).

Vale destacar que o secretário engloba, ainda, atribuições, competências e responsabilidades em nível gerencial, elementos que ampliam as possibilidades de atuação nas diferentes estruturas 
organizacionais, dentre as quais estão: pensamento estratégico, capacidade de identificar oportunidade de crescimento, inovar e elaborar objetivos na organização (Barros, Braga, \& Silva, 2011).

As competências tratadas durante esta seção dão relevância e viabilizam a capacidade gestora presente no perfil contemporâneo do profissional de Secretariado Executivo. Portanto, considera-se, a partir do exposto, ser possível correlacionar aspectos gerenciais ao trabalho desse profissional, fato que justifica o foco deste estudo: análise de possíveis relações entre as competências do profissional de Secretariado Executivo e as do middle manager.

\section{Competências Gerenciais do Middle Manager}

No cenário em que se desenvolveu um novo olhar sobre o papel gerencial, destaca-se o middle manager, agente ocupante de uma posição-chave na organização, dotado de capacidades para combinar estratégias em nível micro e macro, apto a eliminar ruídos e flutuações no ambiente das organizações e, ainda, atuar como um facilitador do processo de autorrenovação e mudança institucional (Nonaka, 1988).

Floyd e Wooldridge (1992) desenvolveram uma tipologia, a qual abrange o envolvimento da gerência intermediária na estratégia (Figura 2), com base em uma investigação que realizaram com 259 middle managers, em 25 organizações. Os autores mencionam, ainda, que a estratégia é um processo de mudança e requer ideias divergentes, que quando colocadas em prática, mudam o conceito organizacional de estratégia.

Os autores argumentam, também, que a estratégia é um "modelo integrado" e requer ideias que coordenam diferentes atividades e dão suporte a direções coerentes. Embora algumas ideias se constituam em pensamentos essencialmente divergentes ou integrativos, reconhecidos como dois polos de um contínuo, fornecem uma base para classificar as contribuições cognitivas da gerência intermediária (Floyd \& Wooldridge, 1992). 


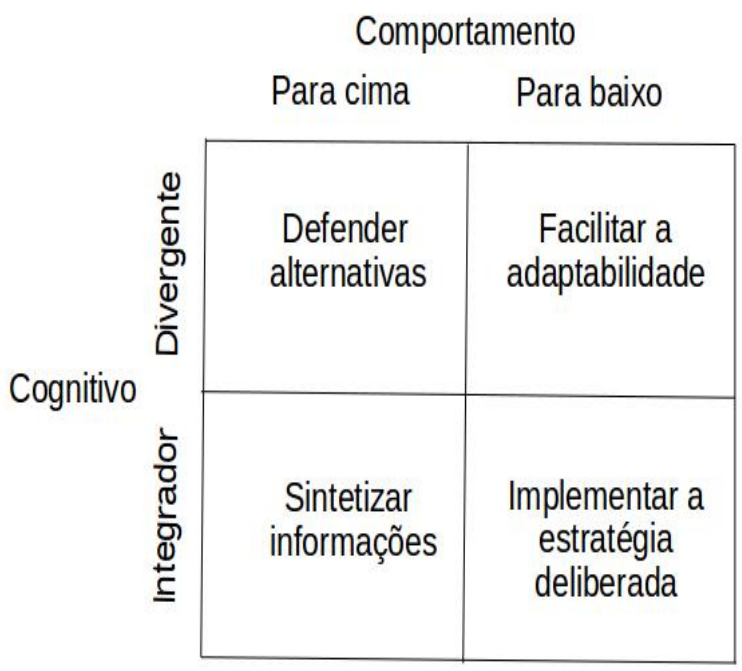

Figura 4. A tipologia da gerência intermediária na estratégia.

Fonte: Floyd e Wooldridge (1992, p. 154).

Ao tratar das tipologias Floyd e Wooldridge (1992) explicam que:

a) defender alternativas: é definida como uma persistente e persuasiva comunicação das opções estratégicas para alta administração; parece constituir uma importante função da gerência intermediária na estratégia e ocorre no sentido ascendente;

b) sintetizar informações: refere-se à interpretação e avaliação da informação, afeta a percepção da alta gerência. E a gerência intermediária, indiretamente, causa influência de modo ascendente na formação da estratégia. A função é integrativa, de modo que ela combina dados ambíguos e diversos, interpretados de acordo com o contexto estratégico fornecido. Com o tempo, porém, essas interpretações subjetivas podem conduzir o trabalho de base para uma mudança estratégica;

c) facilitar a adaptabilidade: definida como adoção de planos organizacionais flexíveis, é uma função estratégica de importância terciária na gerência média; ocorre no sentido descendente;

d) implementar a estratégia deliberada: é comumente considerada a função estratégica-chave na implementação da estratégia deliberada para os gerentes intermediários. Por isso é definida como intenções administrativas que alinham a ação organizacional com as intenções estratégicas. É a quarta função da gerência intermediária incluída na tipologia. Enquanto tais intervenções podem facilitar mudanças, a função é integrativa, visto que ela interliga as atividades organizacionais com as intenções da alta gerência e ocorre de modo descendente (Floyd \& Wooldridge, 1992).

Hornsby, Kuratko e Zahra (2002) mencionam a atuação do middle manager quanto à 
utilização de diferentes abordagens, as quais visam a tornar a estrutura organizacional menos resistente à mudança; tal ato possibilita o desenvolvimento das atividades corporativas. $\mathrm{O}$ middle manager é responsável, ainda, por comunicar e transmitir informações advindas do nível operacional aos gestores da alta administração e vice-versa, pois cabe a ele sintetizar as demandas e os processos em sua área de atuação, de modo a buscar soluções e alternativas que subsidiem a tomada de decisão da cúpula organizacional (Lavarda, Giner \& Bonet, 2010).

A promoção da aprendizagem organizacional está incluída no papel do middle manager por meio da disseminação de conhecimentos e da implementação de estratégias deliberadas; além de atuar como motivador de sua equipe e promover a defesa, ora da posição da alta gerência, ora das necessidades e ideias provenientes dos níveis tático e operacional da organização (Lavarda, Giner, \& Bonet, 2010).

Rouleau e Balogun (2011) argumentam, ainda, sobre a necessidade de compreensão das habilidades argumentativas do middle manager, as quais levam ao envolvimento dos outros membros da organização em seus projetos. Além disso, as autoras tratam da competência desses gerentes em ser "politicamente capazes" para que, se assim o desejarem, possam direcionar o curso de ações relacionadas à estratégia organizacional. Nesse sentido, ressalta-se que o middle manager é considerado:

[...] como peça fundamental no processo de formação da estratégia, como integrador da visão da diretoria, transmitindo os objetivos e a visão prática da realidade organizacional, proporcionada pelos trabalhadores e podendo até intervir e mudar o rumo da organização, com a integração de suas perspectivas de práticas de vida da organização (Machado \& Lavarda, 2011, p. 5)

Por fim, com base no exposto pelos autores apresentados ao longo desta seção, tem-se o contexto das competências gerenciais como um diferencial das organizações, que passam a buscar maneiras de alinhar as habilidades e conhecimentos do gerente às competências organizacionais. Nesse contexto, o middle manager se insere como agente integrador que possui habilidades aplicáveis à consecução de objetivos organizacionais, que contribui para com a implementação da estratégia organizacional e, também, com a mediação de conflitos e com a intervenção nos ambientes interno e externo, além de criar um elo entre a alta gerência e os demais níveis organizacionais. Enfim, o middle manager é considerado um precursor de mudanças, as quais operam em direção ao crescimento organizacional. 


\section{Procedimentos Metodológicos}

A fim de alcançar o objetivo estabelecido, esta pesquisa traz uma combinação de procedimentos metodológicos, os quais pretendem caracterizá-la em termos de cientificidade, rigor e confiabilidade, elementos fundamentais de uma pesquisa qualitativa (Vieira, 2004).

Assim, trata-se um estudo qualitativo, o qual é definido por Roesch (1999, p. 130), como “[...] apropriado para a avaliação formativa, quando se trata de melhorar a efetividade de um programa, ou plano, ou mesmo quando é o caso da proposição de planos. Ou seja, quando se trata de selecionar as metas de um programa e construir uma intervenção [...]”.

Quanto aos objetivos, considera-se um estudo descritivo. Vergara (2007, p. 47) aponta que: “A pesquisa descritiva expõe características de determinada população ou de determinado fenômeno. Pode também esclarecer correlações entre variáveis e definir sua natureza [...].”

Em relação aos procedimentos técnicos, a pesquisa é bibliográfica e documental, embasada em material já elaborado, constituído, principalmente, de busca em periódicos, livros e documentos que versam sobre o tema em discussão (Gil, 2010).

As principais fontes de dados para este estudo foram compostas por artigos científicos e por legislação, ambos provenientes e/ou relacionados às áreas de secretariado e administração. Partiu-se do pressuposto de que poderia haver possíveis relações entre as competências do secretariado executivo e aquelas do middle manager, sendo que o questionamento se deu no sentido de saber quais eram elas.

Dessa maneira, em termos de procedimento, após a identificação das competências do middle manager e da descrição daquelas dos profissionais de Secretariado Executivo, procedeu-se análise de conteúdo, cujas categorias analíticas foram embasadas na Tipologia da Gerência Intermediária de Floyd e Wooldridge (1992), a fim de investigar a correlação entre ambas as competências. O intuito foi identificar a proximidade entre os papéis, e encontrar elementos que viessem a proporcionar indícios de que a atuação do profissional de Secretariado Executivo nas organizações pode refletir, sob determinados aspectos, a equivalência da atuação do middle manager. 


\section{Apresentação e Análise dos Dados}

Estabelecidos os objetivos e aportes teóricos deste trabalho, o qual está focado na correlação existente entre as competências do profissional de Secretariado Executivo e aquelas do middle manager, faz-se a apresentação e análise de dados levantados.

O intuito, conforme já mencionado, não é desconstruir a profissão do secretário executivo, pelo contrário, é trazer elementos que corroborem o fato de esse profissional possuir competências aplicáveis à gestão organizacional e possuir condições de assumir gerências intermediárias nas organizações, sejam elas, públicas ou privadas e em termos de contexto brasileiro.

Farnham (1997 como citado em MacNeil \& Fossey, 2003, p. 37) menciona que o número de secretárias declinou em 20\% em uma década nos Estados Unidos. As que se mantiveram na profissão de secretariado comumente realizam funções de média gerência.

Segundo Machado e Lavarda (2011, p. 5) “As gerências intermediárias podem contribuir para a mudança de visão dos gestores responsáveis pela direção da estratégia, uma vez que nestas funções possuem conhecimento acerca de circunstâncias organizacionais específicas". O profissional de Secretariado Executivo insere-se nesse contexto, diante do conhecimento adquirido durante sua formação e sua posição organizacional, isto é, ao lado daqueles que tomam decisões (Moreira \& Olivo, 2012).

Lavarda, Giner e Bonet (2010) trazem aspectos relativos às responsabilidades do middle manager, ou seja, comunicação e transmissão de informações provenientes do nível operacional aos gestores da alta administração e vice-versa. Além disso, o ocupante dessa posição deve ter capacidade de sintetizar as demandas e os processos em seu campo de atuação, a fim de subsidiar soluções e alternativas que auxiliem na tomada de decisão da cúpula organizacional.

Desse modo, com base no exposto anteriormente, bem como nas demais contribuições trazidas na fundamentação teórica deste estudo, foram estabelecidas categorias de análise de dados, as quais pretendem responder ao objetivo deste estudo, conforme demonstra a Figura 5. 


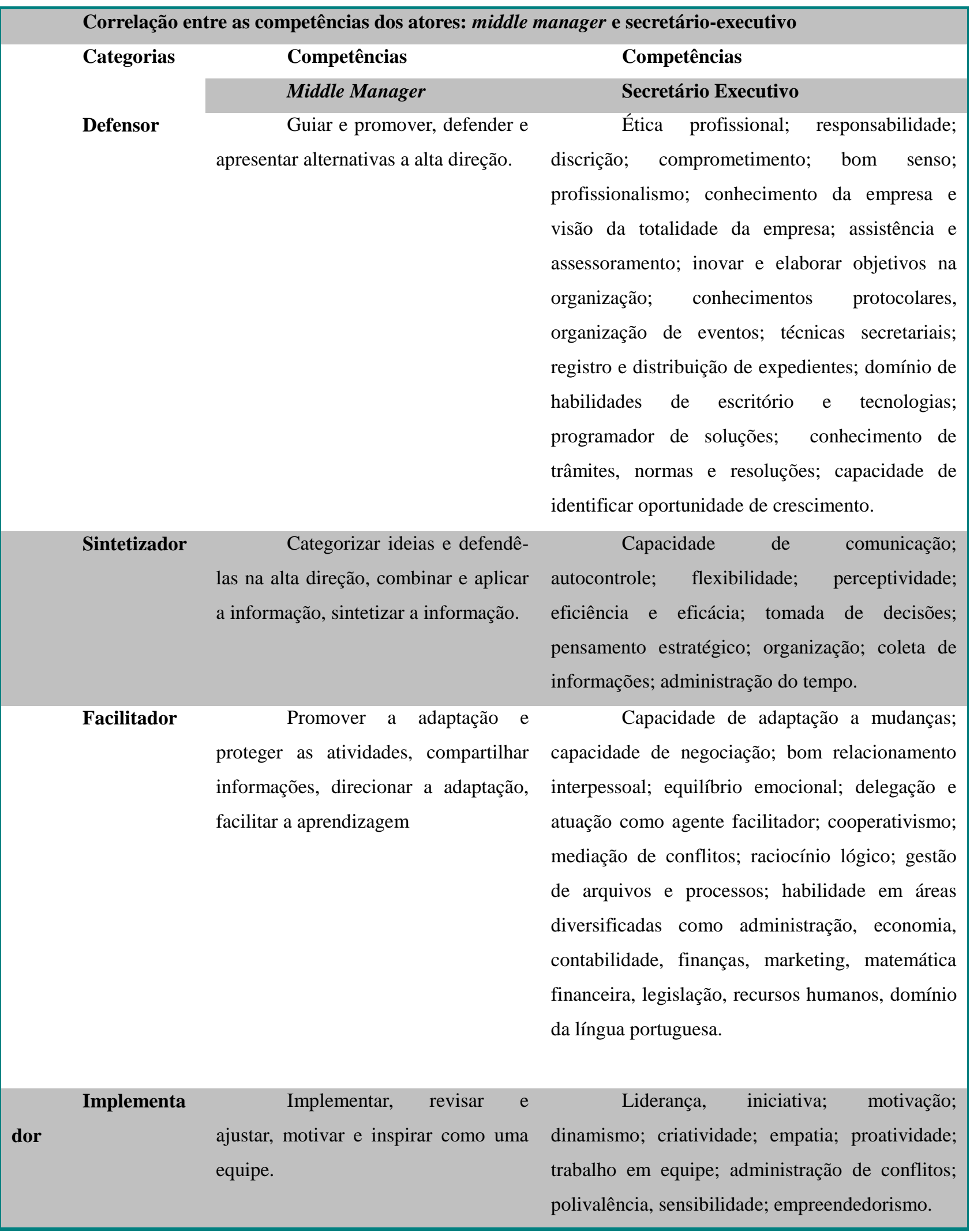

Figura 5. Correlação entre as competências dos atores: middle manager e secretário executivo.

Fonte: Elaborado pelas autoras, com base em: Ministério do Trabalho e Emprego (2002); Resolução da Câmara de Educação Superior n. 3 (2005); Lei n. 6.556 (1978); Lei n. 7.377 (1985); Cordeiro (2009); Lima e Cantarotti (2010); Leal e Dalmau (2014); Floyd e Wooldridge (1992); Lavarda, Giner e Bonet (2010) e Machado e Lavarda (2011). 
A partir da correlação proposta na Figura 5, observa-se que:

$\mathrm{Na}$ categoria de defensor, ou seja, na intenção de atuar como guia e também como defensor e propositor de alternativas a serem submetidas à alta direção, o secretário executivo possui uma gama de competências que atendem a tais requisitos, com destaque para a ética, responsabilidade e uso do bom senso. Neiva e D’Elia (2009, pp. 46-47) reforçam o afirmado quando expõem que:

O desafio do secretário executivo extrapola leitura, triagem e encaminhamento de informações, é necessário conectá-las, tendo como diretriz o conhecimento global. Como profissional que atua ao lado do poder decisório e na posição estratégica de ponte, o secretário é uma das linhas de frente da organização.

Ou seja, há alinhamento entre a atuação do gerente intermediário e do secretário executivo naquilo que diz respeito à categoria defensor. Seguindo no que diz respeito às correlações.

No que se refere à categoria sintetizador - categorizar ideais e defendê-las, combinar, aplicar e sintetizar informações - nota-se o estabelecimento de relação entre as competências do profissional de Secretariado Executivo com as do middle manager. Observa-se que a maioria dos cursos de graduação em secretariado dá ênfase para a questão da informação, conforme destaca os estudos de Nascimento e Silva (2013).

Tal evidência vai ao encontro daquilo que Drucker (1997) discute sobre as organizações necessitarem da informação. O autor explica que as informações são elementos dotados de relevância e propósito, e que para convertê-los é preciso conhecimento especializado. Em outras palavras, é necessário haver efetividade na comunicação para que a informação seja precisa. Desse modo, destacam-se, entre outras, as competências de capacidade de comunicação, perceptividade e eficiência e eficácia no perfil do secretário executivo.

Quanto à categoria facilitador, que envolve o middle manager em questões sobre: promover a adaptação e proteger as atividades; compartilhar informações; direcionar a adaptação e facilitar a aprendizagem, o profissional de Secretariado Executivo também se ajusta a tais competências, principalmente no que concerne a sua capacidade de adaptação, cooperativismo e de ser mediador de conflitos. Moreira e Olivo (2012) constataram que o profissional de Secretariado faz a intermediação das relações do gestor com ambientes internos e externos. Ou seja, é um organizador, um facilitador, que atua nas interações entre os dois espaços. Em relação à categoria implementador, cuja responsabilidade do middle manager é implementar, revisar e ajustar, motivar e inspirar pessoas/equipes. Brito, Nunes e Pontes (2013) constataram, em relação ao secretário executivo, a importância de um correto processo de gestão e liderança e a adequação do comportamento do secretário executivo como líder, capaz de cativar sua equipe e motivá-los, no sentido de alcançar a efetividade das metas organizacionais. Destacam-se, nesse sentido, as competências de liderança, 
iniciativa, motivação e empatia.

Compreende-se por meio do descrito, que a correlação proposta por este estudo foi atendida. Tal resultado é estimulante, pois configura a conquista de novos espaços no ambiente organizacional para o profissional de secretariado, e também, reforça a premissa de que a área de atuação do secretário está cada vez mais alinhada ao nível intermediário e estratégico das organizações e isso se deve ao desenvolvimento de suas competências e superação de desafios.

\section{Conclusões do Estudo}

O campo de atuação do secretário executivo tem se ampliado cada vez mais, proporcionando a ele conquistas de destaque, não apenas em sua profissão, mas, igualmente, no âmbito acadêmico. Se até pouco tempo esse profissional direcionava seus estudos para uma formação preparatória para o mercado, hoje, dedica-se também à pesquisa.

Este estudo teve por objetivo analisar as relações entre as competências do profissional de secretariado e aquelas do middle manager. Ressalta-se que o recorte teórico foi definido com base no contexto brasileiro de atuação desse profissional, no sentido não de descaracterizar a profissão, mas sim de demonstrar, por meio de uma correlação analítica e reflexiva, acerca dos estudos do campo da gestão, que o secretário executivo possui competências que o tornariam apto para atuar no gerenciamento intermediário em uma organização.

A partir disso, considera-se que a problemática deste estudo, qual seja: "Quais são as possíveis relações entre as competências do profissional de secretariado e do middle manager?" foi atendida. Em outras palavras, a partir da definição das categorias de análise estabelecidas neste estudo, as quais foram posteriormente tratadas na análise de conteúdo, encontraram-se elementos que permitem ao secretário executivo, a partir das suas competências, atuar profissionalmente na gerência intermediária.

No que diz respeito aos objetivos específicos, estabelecidos como elementos auxiliares na busca pelo alcance do objetivo deste trabalho observar-se que o primeiro - descrever as competências do profissional de Secretariado Executivo, e o segundo - caracterizar o middle manager e identificar suas competências, foram concentrados na fundamentação teórica, enquanto o terceiro - correlacionar as competências entre profissionais de Secretariado Executivo e do middle manager, foi contemplado na apresentação e análise dos dados. Acredita-se, ao fim da pesquisa, que os dados responderam positivamente ao tema-problema e, como consequência, possibilitou o 
alcance do objetivo principal.

Cabe ressaltar, no entanto, que esta pesquisa adotou uma perspectiva de análise teórica quanto à dialogicidade entre os temas estruturados no capítulo $2 \mathrm{e}$ a busca pela resposta ao objetivo central de investigação. Nesse sentido, ressalta-se como limitação a necessidade de trabalhos empíricos para complementar e/ou confrontar os achados e as conclusões deste estudo.

Desse modo, para futuros trabalhos, sugerem-se pesquisas com profissionais da área de secretariado, com o objetivo de conhecer empiricamente como se daria, em termos de atuação no campo, o desempenho do secretário-executivo na gerência intermediária, ou seja, como um middle manager, bem como quais seriam os desafios disso.

Portanto, infere-se a partir dos elementos trazidos nesta pesquisa que a posição de middle manager emerge no mercado como uma possibilidade para profissionais de áreas diversas do conhecimento, inclusive a de Secretariado Executivo, fato que valoriza e amplia as possibilidades de atuação em sua carreira.

\section{Referências}

Azevedo, I., \& Costa, S. I. (2002). Secretária: um guia prático (3a ed.). São Paulo: Senac.

Barros, C. M. P., Braga, M. C., \& Silva, J. S. (2011). As competências gerenciais na atuação do secretário executivo no nível estratégico. Revista Expectativa, 10(10), 91-106.

Bortolotto, M., \& Willers, E. (2005). Profissional de Secretariado Executivo: Explanação das principais características que compõem o perfil. Revista Expectativa, 1(4), 45-56.

Boyatzis, A. R. (1982). The competent manager: a model for effective performance. New York: John Wiley e Sons.

Brito, D. G. S., Nunes, L. G., \& Pontes, M. D. V. S. (2013, maio). O Secretário Executivo como líder e gestor de pessoas: uma abordagem descritiva dos desafios enfrentados. Anais do XII Semissec, Porto Seguro, BA, Brasil, 12. Recuperado em 24 março, 2015, de http://www.fenassec.com.br/xii_semissec2013_artigos/osecretario-executivo-como-lider-e-gestor-de-pessoas.pdf.

Bündchen, E.; Rossetto, C. R., \& Silva, A. B. da (2011). Competências gerenciais em ação: o caso do Banco do Brasil. Revista Eletrônica de Administração, 17(2), 396-423. Recuperado em 30 março, 2015, de http://www.seer.ufrgs.br/index.php/read/article/view/38530.

Burgoyne, J. G. (1993). The competence movement: issues, stakeholders and prospects. Personnel Review, 22(6), 6-13. Recuperado em 30 março, 2015, de http://www.emeraldinsight.com/doi/pdfplus/10.1108/EUM000000000081. 
Carvalho, M. S. M. V. (1998). Gestão de competências: Uma nova (?) abordagem em recursos humanos. Revista de Administração Pública, 32(5), 162-71. Recuperado em 30 março, 2015, de: http://bibliotecadigital.fgv.br/ojs/index.php/rap/article/view/7761.

Cordeiro, R. L. (2009). Competências complementares: secretário executivo e administrador trabalho final de graduação em secretariado executivo bilíngue. Monografia de Graduação.

Universidade de Passo Fundo, Passo Fundo, Rio Grande do Sul.

Drucker, P. F. (1997). As novas realidades: no governo e na política, na economia e nas empresas, na sociedade e na visão do mundo (4a ed.). (C. A. Malferrari, Trad.). São Paulo: Pioneira.

Dutra, J. S. (2009). Competências: conceitos e instrumentos para a gestão de pessoas na empresa moderna. São Paulo: Atlas.

Filenga, D.;, Moura, V. F., \& Rama, A. L. F. (2010, setembro). Gestão por competências: análise metodológica e proposição de um instrumento para gestão de pessoas. Anais do XXXIV Encontro da AnpadEnanpad, Rio de Janeiro, RJ, Brasil, 34.

Fleury, A., \& Fleury, M. T. L. (2004). Estratégias empresariais e formação de competências: um quebracabeça caleidoscópico da indústria brasileira (3a ed.). São Paulo: Atlas.

Floyd, S. W., \& Wooldridge, B. (1992). Middle management involvement in strategy and its association with strategic type: a research note. Strategic Management Journal, 13, 153-167.

Garcia, E. V. (1999). Muito prazer sou a secretária do senhor: um estudo sobre a profissional secretária a partir da análise do discurso. Passo Fundo: Elisabeth Virag.

Garfield, E. (1986). From scribes to secretaries in 5000 years; from secretaries to information managers in 20. Current Contents, 9(15), 3-8.

Gil, A. C. (2010). Como elaborar projetos de pesquisa. São Paulo: Atlas.

Hornsby, S. J.;, Kuratko, F. D., \& Zahra, A. S. (2002). Middle managers' perception of the internal environment for corporate entrepreneurship: assessing a measurement scale. Journal of Business Venturing, $17,253-273$.

Lasta, A., \& Durante, D. G. (2008). A gestão secretarial no cenário organizacional contemporâneo. Secretariado Executivo em Revista, 4, 49-65.

Lavarda, B. A. R.; Giner-Cantet, T. M., \& Bonet-Peris, J. F. (2010). How middle managers contribute to strategy formation process: connection of strategy processes and strategy practices. Revista de Administração de Empresas, 50(4), 358-370.

Le Boterf, G. (1994). De la compétence. Essai sur un attracteur étrange. Paris: Les Editions d'organisation.

Leal, F. G., \& Dalmau, M. L. B. (2014). Análise das competências secretariais requeridas pela Universidade Federal de Santa Catarina em comparação ao perfil profissiográfico do secretário executivo. Revista de Gestão e Secretariado, 5(3), 143-174.

., \& Fiates, G. G. (2013). Competências dos secretários executivos de uma universidade pública federal: uma análise a partir da perspectiva dos gestores. Revista de Gestão e Secretariado, 4(3), 30-57. 
Lei $n$. 6.556, de 5 de setembro de 1978 (1978). Dispõe sobre a atividade de Secretário e dá outras providências. Brasília, DF. Recuperado em 24 março, 2015, de http://www2.camara.leg.br/legin/fed/lei/1970-1979/lei-6556-5-setembro-1978-366543-publicacaooriginal-1pl.html.

Lei $n$. 7.377, de 30 de setembro de 1985 (1985). Dispõe sobre o exercício da profissão de Secretário e dá outras providências. Brasília, DF. Recuperado em 24 março, 2015, de http://www.planalto.gov.br/ccivil 03/leis/L7377.htm.

Lima, T. F., \& Cantarotti, A. (2010). A formação e a construção de competências para a atuação do profissional de Secretariado Executivo: um estudo de caso de uma empresa júnior. Revista de gestão $e$ secretariado, 1(2), 94-122.

Machado, A. J., \& Lavarda, B. A. R. (2011, maio). Os papéis que o middle manager desempenha na formação e implementação da estratégia. Anais do V Encontro de Estudos em Estratégia, Porto Alegre, RS, Brasil, 5.

MacNeil, A., \& Fossey, R. (2003). The case of secretary versus principal or the recalcitrant secretary. Journal of Cases in Educational Leadership, 6(3), 33-40. Recuperado em 22 março, 2015, de http://doi.org/10.1177/155545890300600304

McClelland, D. C. (1973). Testing for competence rather than for intelligence. American Psychologist, 28(1), 1-14. Recuperado em 22 março, 2015, de http://dx.doi.org/10.1037/h0034092.

Magalhães, S. J.;, Wanderley, M. H., \& Rocha, J. (1997). Desenvolvimento de competências: o futuro agora! Revista Treinamento e Desenvolvimento, 3(14), 12-14.

Mattos, V. (2000). Supersecretária (2a ed.). São Paulo: Nobel.

Ministério do Trabalho e Emprego. (2002). Classificação Brasileira de Ocupações - CBO. Recuperado em 22 março, 2015, de: http://www.mtecbo.gov.br/cbosite/pages/downloads.jsf.

Moreira, K. D., \& Olivo, L. C. C. (2012). O Profissional de Secretariado Executivo como mediador de conflitos. Revista de Gestão e Secretariado, 3(1), 30-53.

Nascimento, I. B. N. , \& Silva, G. L. (2013). A informação e suas tecnologias: uma análise descritiva e correlativa das ementas das disciplinas de informática em cursos de bacharelado em Secretariado Executivo de instituições públicas de ensino superior no Brasil. Revista de Gestão e Secretariado, 4(3), 1-29.

Natalense, M. L. C. (1995). Secretária executiva: manual prático. São Paulo: IOB.

Neiva, E. G., \& D’Elia, M. E. S. (2009). As novas competências do profissional de secretariado (2a ed.) São Paulo: IOB.

Nonaka, I. (1988). Toward middle-up-down management: accelerating information creation. Sloan Management Review, 29 (3), 9-18.

Paiva, K. C. M., Ésther, A. B., \& Pires, A. C. R. (2006). Milícias, malícias e delícias da função gerencial: o setor hoteleiro em foco. Revista Turismo em Análise. Recuperado em 30 março, 2015, de: http://www.revistas.usp.br/rta/article/view/63759.

Pereira, A. L. C., \& Silva, A. B. (2011, julho). As competências gerenciais nas instituições federais de 
educação superior. Cadernos EBAPE.BR, 9, 632-647. Recuperado em 22 março, 2015, de http://bibliotecadigital.fgv.br/ojs/index.php/cadernosebape/article/view/5445.

Portela, K. C.A., \& Schumacher, A. J. (2009). Gestão secretarial: o desafio da visão holística (1a. ed.). Cuiabá: Adeptus.

Prahalad, C. K., \& Hamel, G. (1990). The core competence of the corporation. Harvard Business Review, 68(3), 79-91.

Rabaglio, M. O. (2001). Seleção por competência. São Paulo: Educator.

Resende, E. (2000). O livro das competências: desenvolvimento das competências: a melhor auto-ajuda para pessoas, organizações e sociedade. Rio de Janeiro: Qualitymark.

Resolução CES no 3, de 23 de junho de 2005 (2005). Estabelece diretrizes curriculares nacional dos cursos de graduação em secretariado executivo. Diário Oficial da União, Brasília, DF. Recuperado em 24 março, 2015, de http://portal.mec.gov.br/cne/arquivos/pdf/rces003_05.pdf.

Roesch, S. M. A. (1999). Projetos de estágio e de pesquisa em administração: guia para estágios, trabalhos de conclusão, dissertações e estudos de caso (2a ed.). São Paulo: Atlas.

Rouleau, L., \& Balogun, J. (2011). Middle managers, strategic sensemaking, and siscursive competence. Journal of Management Studies, 48(5), 953-983.

Ruas, R. (2005). Gestão por competências: uma contribuição à estratégia das organizações. In R. Ruas, C. S. Antonelo, \& L. H. Boff (Orgs.). Aprendizagem organizacional e competências: os novos horizontes da gestão. Porto Alegre: Bookman.

Seiblitz, V. M. L. (1999). Super Secretária: o guia para a profissional que quer vencer na vida. São Paulo: Nobel.

Taylor, F. W. (1970). Princípios da administração científica. São Paulo: Atlas

U. S. Department of Labor, Office of the Secretary, Women's Bureau. (1985). Women and office automation; issues for the decade ahed. Washington, D. C.: Government Printing Office.

Vergara, S. C. (2007). Projetos e relatórios de pesquisa em administração. São Paulo: Atlas.

Vieira, M. M. F. (2004). Por uma boa pesquisa (qualitativa) em administração. In M. M. F. Vieira \& D. M. Zouain (Orgs.). Pesquisa qualitativa em administração. Rio de Janeiro, RJ: FGV Editora.

Weymer, A. S. Q., \& Silva, E. D. (2009, novembro). A contribuição do conceito de competências nos campos científico e gerencial: um tour sobre pesquisas empíricas e suas relações epistemológicas. Anais do II Encontro de Gestão de Pessoas e Relações de Trabalho, Curitiba, PR, Brasil, 2.

Zarifian, P. (1994). Compétences et organisation qualifiante en milieu industriel. Lacompétence: mythe, construction ou réalité. Paris: Liaisons. 